Journal of Finance and Investment Analysis, Vol. 10, No. 4, 2021, 1-14

ISSN: 2241-0998 (print version), 2241-0996(online)

https://doi.org/10.47260/jfia/1041

Scientific Press International Limited

\title{
Failure of Lehman Brothers
}

\author{
Mahmoud Mofid Abdul Karim ${ }^{1}$
}

\begin{abstract}
This study assessed the failure of the Lehman brothers. The aim was to evaluate the causes of Lehman's bankruptcy and determine the strategies that could prevent bankruptcy in the banking sector going forward. Findings indicated a close relationship between regulations and the actions of management. In particular, the failure of Lehman showed that regulation and supervision are critical to the success and continuity of the banking sector. The analysis also showed that the demise of Lehman was a result of complex factors. These included unethical management practices, deregulation, excessive risk-taking, poor corporate governance structure, fraud, and lack of a robust ethics code.
\end{abstract}

Keywords: Derivatives, Hedging, Subprime Mortgage, Bankruptcy.

1 SMC University. Switzerland

Article Info: Received: August 15, 2021. Revised: September 2, 2021.

Published online: September 7, 2021. 


\section{Introduction}

Lehman Brothers Holdings (hereafter Lehman) was a US-based multinational company engaged in providing financial services. The bank started as a dry-goods store in 1850. However, the bank grew and expanded to become one of the largest banks in the US. For instance, the bank was the fourth-largest bank in the US in the fourth quarter of 2007 (Chadha, 2016). It offered a wide range of solutions, including investment banking, investment management, private banking, fixed-income sales, and securities (Chadha, 2016). The bank reported a net income of $\$ 4,192$ million in 2007 , representing a 5\% increase in the previous year's profit of $\$ 4,007$ million. Its cash and cash equivalents also increased significantly from $\$ 5,987$ million in 2006 to $\$ 7,286$ million in 2007 . Therefore, the bank was healthy and financially strong in 2007.

Lehman ran into difficulties in early 2008 despite posting strong financial results in 2007. It failed to raise cash to fund operations such as debt repayment. The problem worsened in early 2008 due to customers' mass exodus and drastic stock value losses (Wiggins et al., 2019). Besides, the bank failed to secure a solid strategic partner to acquire some of its subsidiaries (Wiggins et al., 2019). The bank later filed for chapter 11 protection on September 15, 2008. The filling showed that Lehman closed its doors with $\$ 639$ billion in assets and $\$ 613$ billion in debts. The bankruptcy resulted in a series of events that unfolded in the stock market. For instance, the DJIA declined by more than 500 points immediately after Lehman Brothers' bankruptcy (Chadha, 2016). The bank's collapse also led to an enormous movement in the money market. The electronic money market had to be closed due to the loss of investor confidence and the mass movement of cash (Chadha, 2016). This report examines the causes of Lehman Brothers' failure and whether the failure was avoidable. The report uses reliable data sources to achieve reliable findings and recommendations for banks going forward.

\section{Lehman's Status Before Bankruptcy}

\subsection{Lehman History}

Lehman had a humble beginning as a general store. It started in 1844 in Montgomery when three brothers opened a general store to dry goods. The company later diversified its product portfolio by trading other commodities and helping firms raise capital in the equity and bond markets (Wiggins et al., 2019). It became an NYSE member in 1887 and established itself in the security trading and underwriting business. Its reputation solidified between 1925 and 1969 under Robert Lehman's leadership (Wiggins et al., 2019). During such a period, the bank worked closely with leading companies (local and international) in providing financial advice, underwriting securities offerings, and assisting in M\&A transactions. The company ran as a family-controlled business and as a partnership up until Robert died in 1969. 


\subsection{Acquisition and Divestment}

Lehman experienced a period of drift following Robert Lehman's death (Wiggins et al., 2019). However, the company brought in Peter G. Peterson in 1973 as the CEO. The bank favored the new CEO due to his influence in the investment banking practice. He relied on his power to lead the company to become profitable. The bank established offices outside the US and became a global firm. It carried its activities through three operating segments: capital markets, client services, and investment banking (Wiggins et al., 2019). The bank, however, went through a period of "declients" as clients selected investment banking suppliers on a deal-by-deal basis (Wiggins et al., 2019, p.42). Also, the target clients sought sophisticated solutions and chose the best deal on offer (Wiggins et al., 2019).

Internal conflicts broke out between investment bankers and traders during the early 1980s. The bank had to resolve the disputes to ensure that it did not negatively affect its performance. For instance, it hired Glucksman as a CEO to help steer the bank in the right direction. However, Mr. Glucksman was unable to resolve the underlying problems. Therefore, the owners chose to sell the firm as profits weakened in 1984. The new owner, American Express, merged Lehman with Shearson to form what was then called Shearson Lehman Brothers. However, the firm decided to split the new formation to focus on travel and personal finance (Wiggins et al., 2019). Lehman focused on personal finance, which was its core business. It went public in 1994 by issuing an IPO which helped raise over $\$ 3$ billion.

\subsection{Expansion and Growth}

Lehman expanded its product portfolio in the early 2000s (Wiggins et al., 2019). The expansion was after the repeal of the Glass-Seagal Act of 1933. The bank introduced new complex and riskier financial solutions. The new product introduction's main aim was to help the bank leverage new opportunities presented by the deregulated market (Wiggins et al., 2019). The bank, for instance, engaged in real estate, asset management, securitization, and property trading (Wiggins et al., 2019). Property trading, however, became the core business as it accounted for $21 \%$ of Lehman's product portfolio. The change in business composition led to a substantial increase in market capitalization, as depicted below. 


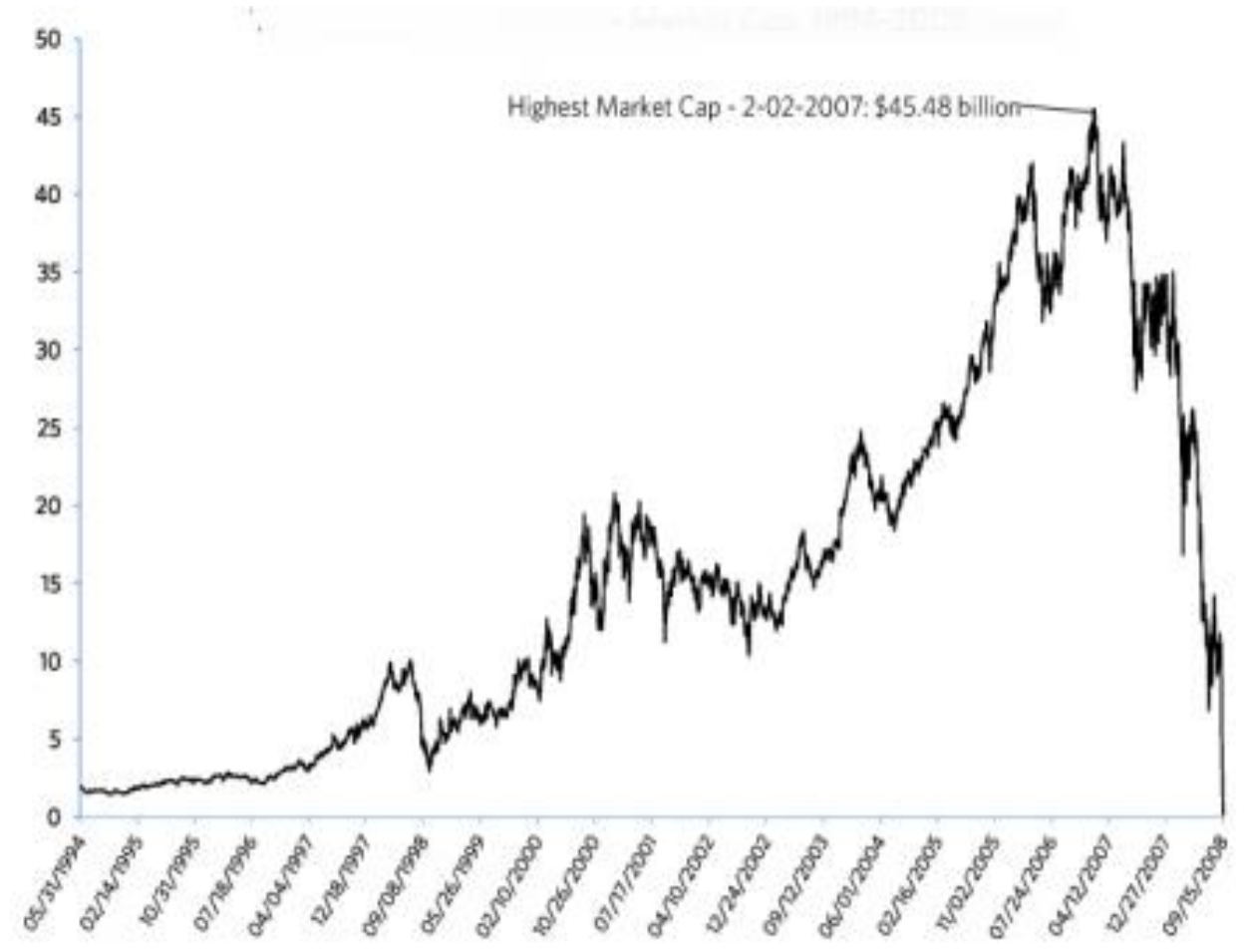

Figure 1: Lehman's market cap in billion US\$ (Wiggins et al., 2019)

The above chart shows that Lehman's market capitalization between 2000 and 2006. The market cap grew significantly during that period to reflect Lehman's strong performance. For instance, the bank's sales grew by $130 \%$ to outpace its main rivals, Morgan Stanley and Goldman Sachs. The equity market recognized such growth by increasing the firms' share price so that the bank's market cap increased by $340 \%$ between 1994 and 2006 (Wiggins et al., 2019).

\subsection{Lehman in 2006 and 2008}

The market for subprime mortgages and mortgage-backed securities (MBS) rapidly expanded between 2004 and 2007. The main driver for growth was the high demand in the housing market. Initially, large banks purchased mortgages to include them in their MBS. However, Lehman expanded its operations to include loan origination as securitization become a profitable business. It acquired five mortgage lenders between 2003 and 2004. The acquisition led to Lehman becoming the leading market-maker and underwriter of commercial and residential MBS. The company was also active in every area related to securitized products, structured finance, and securing lending.

In March 2006, market warnings showed that the housing market was at its peak. However, Lehman introduced a new strategy to capitalize on its experience in the market. The plan assumed that the bank could succeed by pursuing the countercyclical strategy, which was successful in the 1980s. Under the new strategy, the 
investment bank would acquire assets and hold them in its balance sheet. Therefore, returns and risks of the acquired assets were retained in the bank's books hoping that returns could improve in the near future. However, the strategy was in contrast to the previous approach, where the bank would acquire assets and move them to clients through securitization (Wiggins et al., 2019). The new aggressive approach allowed the bank to acquire a large portion of real estate-related securities and assets in 2006. However, the high portion of assets made it hard for the bank to raise funds, lower leverage, and hedge against risks. Besides, holding many risky assets attracted investors and rating agencies' concerns as the assets were highly illiquid (Wiggins et al., 2019). As a result, the firm had to constantly revalue and write off the assets throughout 2008 to show their fair values.

\subsection{Leverage Concerns}

Leverage is a core measure of a company's capital adequacy. Lehman calculated its leverage by dividing assets by shareholders' equity. However, the company's leverage increased significantly between 2003 and 2007, as indicated below.

Table 1: Lehman's leverage ratio from 2003 to 2007 (Wiggins et al., 2019)

\begin{tabular}{|c|c|c|c|c|c|}
\hline Year & $\mathbf{2 0 0 7}$ & $\mathbf{2 0 0 6}$ & $\mathbf{2 0 0 5}$ & $\mathbf{2 0 0 4}$ & $\mathbf{2 0 0 3}$ \\
\hline $\begin{array}{c}\text { Leverage } \\
\text { Ratio Reported* }\end{array}$ & $30.7 \mathrm{x}$ & $26.2 \mathrm{x}$ & $24.4 \mathrm{x}$ & $23.9 \mathrm{x}$ & $23.7 \mathrm{x}$ \\
\hline
\end{tabular}

The above figure shows that Lehman's leverage increased significantly in 2007. The increased use of leverage was, however, similar to almost all big firms. The strategy allowed the banks to pursue growth opportunities and enhance their profitability. However, high leverage led to increased scrutiny from analysts and credit rating agencies. The banks had to reduce leverage by selling assets or issuing equity. Lehman chose to raise $\$ 6$ billion by issuing new equity early in 2008 . The bank also embarked on a de-leveraging strategy to assist in reducing leverage. However, the strategy was unsuccessful as the bank failed to sell its real estate assets due to low market prices (Wiggins et al., 2019).

\subsection{Repo 105 Transactions}

Lehman attempted to buy time as solutions failed to materialize. It did this by exceeding its risk limits and manipulating the balance sheet to appear healthier (Wiggins et al., 2019). For instance, it failed to include risky assets in the balance sheet to foul creditors into believing that the bank was creditworthy. Overall, repo 105 helped remove over $\$ 50$ billion of assets from Lehman's balance sheet (Carney, 2010). However, the bank did not disclose such transactions in SEC filings. 


\subsection{Liquidity Problems}

Lehman funded its long-term assets using current debt (such as commercial paper and repo agreements). It also borrowed heavily in the overnight wholesale funding sector to fund operations. Such borrowing increased marginally in early 2008, making other institutions demand more security for a lower level of funds. The development eroded the banks' capacity to continue to finance their current financial obligations. This situation was exacerbated by the withdrawal of some creditors and the refusal to accept the bank's Repos. Some lenders refused to accept Lehman's real-estate-related assets as collateral (Wiggins et al., 2019). In turn, this rendered the assets ineffective and increased the banks' default risk. Figure 3 below shows that Lehman's default risk increased significantly between January 2008 and March 2008 .

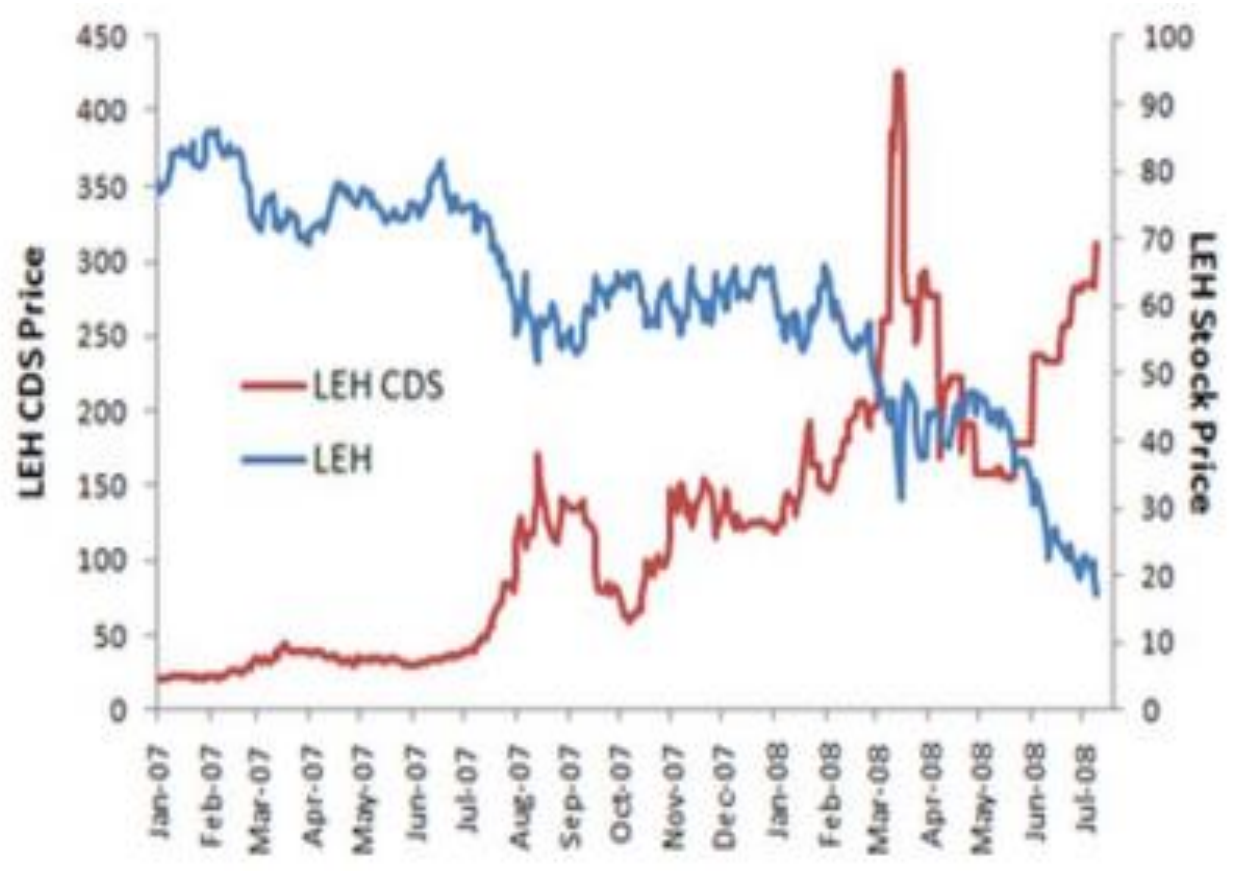

Figure 2: Lehman's stock vs. default risk (Wiggins et al., 2019, p.48)

The above chart shows that market opinion on Lehman's health declined marginally from July 2007. The bank's liquidity position and default risk also increased marginally during the same period.

\subsection{Search for Solution}

Lehman considered several options: a spin-off of toxic assets, a sale transaction, an issue of equity, and capital infusion. It, however, managed to raise $\$ 6$ billion in additional capital, which was not enough as it could not allow the bank to continue operating as a going concern. Besides, the bank failed to secure a sale transaction by September 15, 2008. The news of a possible failure reached rating agencies such 
as Moody's, who responded by downgrading the bank's debt rating. As a result, the bank sought the protection of chapter 11 as it could not operate without funds.

\section{Discussion of Facts and Issues}

The US banking industry experienced a period of stability since the great depression of the 1930s. Most of the banks and financial institutions weathered through the storms of the oil crisis (1973), Mexico crisis (1982), and the Asian financial crisis (1997) with ease (Chadha, 2016). The above was partly because of the protection of the Banking Act of 1933. The act was commonly known as the Glass-Steagall Act of 1933. It effectively separated investment banking from commercial banking and created the federal deposit insurance corporation (Mawutor, 2014). The act also provided safer and more effective use of banks' assets and prevented undue diversion into speculative operations. For instance, the act ensured that banks did not engage in risky investments such as the subprime mortgage business.

The Glass-Steagall act was later replaced in 1999 by the Gramm-Leah-Biley Act (GLBA) 1999. The GBLA was a bi-partisan regulation intended to update and modernize the US financial industry. It, however, repealed the Glass-Steagall act by allowing commercial banks to undertake investment banking activities. Besides, many commercial banks, including Lehman, merged with investment banks to compete with other commercial banks (Mawutor, 2014). Such a strategy exposed the banking industry to several risks, which ultimately led to Lehman's bankruptcy. For instance, the bank could acquire real-estate-related assets and store them in the hope of selling them at a high profit.

Banks approved large amounts of loans during the 2000s (Chadha, 2016). Most of these loans were in the subprime division of the mortgage market. The subprime division granted loans to individuals with poor credit scores. Such individuals were more likely to default on the loans as their ability to pay was low. However, US banks granted subprime mortgages to individuals and companies in the US. The loans were securitized and then sold to the target investors. The subprime loans' originators wanted to shift risk down the line and thus did not care to evaluate the financial system's spread. The main issue that prevented most firms from evaluating the spread was the lack of transparency within the financial system. Thus, through caution to the wind, most banking institutions chose to offer large loans through their subprime divisions.

Lehman introduced the Repo 105 program in 2001 (Presley \& Jones, 2014). The bank approached its European brokers and Linklaters law firm to help ensure that the program did not contravene the English law (Presley \& Jones, 2014). Traditionally, the bank would manage its short-term cash using repurchase agreements. However, in 2007, the transactions took an unusual spin that made the balance sheet look healthier (Azadinamin, 2013). It was, therefore, an accounting gimmick that allowed Lehman to classify short-term loans as a sale. The company used the loophole to hide the fact that it was a high-leverage company during the financial crisis. The bank was, however, highly levered as it had a leverage ratio of approximately $30.7 x$. 
The ratio had increased scientifically since 2004 due to the aggressive growth strategy by Lehman (Wiggins et al., 2019). Lehman supported most of its assets by debt (Chadha, 2016). In particular, the bank acquired $99 \%$ of its assets using debt capital. The implication is that the main stakeholders in Lehman were debtholders. The CEO, Richard S. Fuld Jr., owned roughly $2.4 \%$ of the outstanding common stock, which was more than $50 \%$ of common stock held by directors and officers (Chadha, 2016).

National house prices and sales fell drastically in March 2007. According to NAR data, medium house prices fell by $6 \%$ to $\$ 217,000$ from a peak price of $\$ 230,200$ in June 2006 (Trejos, 2007). Such a fall represented the steepest plunge in house prices since the savings and loan crisis of 1989. The fall in price reduced the value of real estate-related assets held by banks such as Lehman. Besides, US subprime borrowers began to default on their mortgage repayment. Trust was also eroded from the financial markets as no one was fully aware of the extent to which banks were exposed to securitized mortgage loans. In turn, this made it extremely hard for banks to evaluate their risk exposure. They could also not leverage the interbank market to access funds due to falling asset prices. Under the circumstance, banks rushed for exit from the subprime market, pushed the market into a downward spiral, and reduced thin capital cushions for banks.

Lehman increased its use of Repo 105 and Repo 108 transactions (Chadha, 2016). The main was to help eliminate the security inventory from the company balance sheet and reduce net leverage before reporting periods. The repo transactions are not illegal, but Lehman tailored them in a manner that effectively overstated its financial position. The senior executives were fully aware of the transactions' impacts but did not disclose them in the annual reports (Azadinamin, 2013). It misled the users of the statements by misrepresenting the true position of the bank. Therefore, the bank violated the Sarbanes-Oxley Act, aiming to restore investor confidence (Azadinamin, 2013). The law requires firms to improve the quality of their financial statements by providing all the information relevant to users. However, in Lehman's case, the company chose to violate the Sarbanes-Oxley act by providing misleading information in its annual accounts.

The US banks were subject to supervision by the US government and industry organizations (Wiggins et al., 2019). The primary regulators included the SEC, thrift supervision office, the Chicago mercantile exchange, and the New York reserve bank. Such regulators were supposed to provide oversight into Lehman's activities (Wiggins et al., 2019). They had to constantly monitor the bank's activities to ensure that it did not violate the law (e.g., the Sarbanes-Oxley act). Besides, the US government had bailed the Bear Stearns when it was near collapse in March 2008. Therefore, many stakeholders expected the government to play a similar role in Lehman to stop bankruptcy. However, the government did not take an active role in the prevention of the firm's failure. Instead, the SEC, who knew about Lehman's shortcomings, chose not to take decisive action on the bank (Presley \& Jones, 2014). The proxy statement for the 2008 annual meeting showed that non-management directors were highly paid (Chadha, 2016). For instance, a non-management 
director received $\$ 365,000$ in excess of director fees. The bank paid a minimum sum of $\$ 325,000$ to all nine directors (Chadha, 2016). Additionally, eight directors had investment or brokerage accounts with Lehman. Six had invested in partnerships that traded with the bank. Four served on the boards of companies that provided revenue to the bank (Chadha, 2016). Therefore, while NYSE considered nonmanagement directors independent, most of them had financial ties to the company. The underlying implication is that there was a high chance of a conflict of interest. For instance, non-management directors who served on the boards that supplied revenue to Lehman could have manipulated the revenue for their gain.

\section{Analysis of the Facts and Issues}

The introduction of the Gramm-Leach-Bliley Act incentivized banks to engage in previously banned gambling practices. For instance, deregulation motivated Lehman to create a high risk-taking culture. It implemented the culture by aggressively involving itself in the subprime loans market. The market provided loans that were considered inferior quality and had a higher default risk. The loans formed a significant part of Lehman's balance sheet and consequently increased its probability of failure. The bank also engaged in selling collateralized debt obligations (CDOs) to its clients and took a short-term position that effectively eroded such securities' value. It also aggressively purchased real-estate-related assets and hold them on its balance sheet. Under normal circumstances, the bank would move the assets to third parties through securitization. However, it stored the assets in the hope of selling them at a high price and generating more profits. The extensive portfolio of assets increased Lehman's riskiness as the assets were illiquid. Falls in house prices in 2006 and the bank's failure to dispose of the real estate assets resulted in defaults. For instance, the bank could not access funds using the assets as collateral as creditors feared that the assets would continue to lose value.

Fraud is another major cause of Lehman's collapse. E\&Y helped Lehman engage in massive accounting fraud (Chadha, 2016). The scheme entailed using repurchase transactions to remove tens of billions of securities from Lehman's balance sheet. The bank amplified the use of repo transactions as the need to reduce leverage increased. The senior managers chose to exceed Lehman's internal risk limit to manipulate its liquidity pool. The bank's former employees acknowledged that the Repo 105 transactions were accounting tricks and a lazy way of managing the balance sheet (Chadha, 2016). The management formed and used two rules in applying the Repo 105 dealing: 80/20 rule and $120 \%$ rule. The two rules prescribed the minimum level of Repo applications throughout the year and a maximum volume of Repo 105 dealings in each year's fourth quarter. The two rules resulted in the manipulation of Lehman's financial accounts. In the first half of 2008, the two rules helped reduce the bank's balance sheet by $\$ 50$ billion. That amount had a significant and material impact on the leverage ratio, which decreased from $13.9 \mathrm{x}$ to $12.1 \mathrm{x}$ (Carney, 2010). However, the lazy way of de-levering the bank raised concerns among investors and rating agencies. For instance, Moody's lowered its debt rating 
after failing to find a solid strategic partner. Inventor confidence in the company also declined as the company was not transparent in its operations - these issues combined to hurt further the bank's ability to secure funding.

Power was concentrated and centralized in the board's chairman and CEO. For instance, Fuld controlled more than 50\% of the company's voting rights as he held over $50 \%$ of the outstanding common shares. The other directors and officers had the remaining votes, which were not significant to influence significant decisions. Fuld, the CEO, made significant financial decisions for the company. He, for instance, oversaw the reduction of leverage to maintain credit ratings and ensure the bank's survival. He, however, failed to inform the board members of the effect of repo transactions on the bank's operations and financial statements. The repo dealings were made known later in 2008. The audit committee acted appropriately to remedy the situation. However, many of the bank's shortcomings were avoidable. Presley \& Jones (2014) suggests that the bank needed to enhance board expertise, increase board independence, and reduce its CEO to prevent a crisis. For instance, reducing the CEO's power could have been critical in reducing the need to engage in fraudulent Repo dealings.

Lehman's collapse could be associated with ethics. According to the international federation of accountants (2014), the bank was supposed to adhere to five ethical doctrines. These include integrity, due care, professionalism, confidentiality, and professional competence. However, the bank's management chose to violate the doctrines by engaging in account manipulation. Repo transactions to remove billions of dollars in borrowings from the balance sheet constituted a violation of the professionalism and integrity principles. However, a robust code of ethics could have prevented unethical practices. Such a code could have guided the behavior of the CEO and other managers to behave ethically.

Lehman management ignored all warning signs. For instance, it ignored the sufficient warnings issue before the credit market crunch. Such warnings included the tightening of the global credit market, which occurred six months before the market's contraction. The warnings demanded that the bank enhance its debt-to-equity ratio to better respond to unfavorable market conditions. However, the management ignored such warnings by retaining a high portion of illiquid investments. The bank also aggressively purchased real estate-related assets throughout 2005 despite warnings that the real estate market had peaked. The management thought they could leverage their significant experience to profit by speculating on the real estate market. They purchased and held large portions of assets in the hope of selling them at a high profit. More surprising, the bank continued to originate subprime mortgages and increase its real estate holdings when most parties exited the market. Such actions put the bank at a higher risk of bankruptcy, especially during the subprime crisis of 2008. 


\section{Conclusion}

The failure of the Lehman Brothers was the largest in the US banking history. It showed a close relationship between regulations and the actions of management. in particular, the failure of Lehman indicates that regulation is critical to the success and continuity of the banking sector. Consequently, there exists a need for strict regulation of specific bank performance indicators, including solvency, liquidity, and profitability. The analysis has also shown that the demise of Lehman was a result of several complex factors. These included unethical management practices, deregulation, excessive risk-taking, poor corporate governance structure, fraud, and lack of a robust ethics code. For instance, deregulation of the banking sector allowed Lehman to engage in excessive risk-taking. It engaged in the subprime mortgage market, which was excessively risky. It also purchased large portions of real-estaterelated assets and held them despite the warnings that indicated that the market had peaked.

The analysis has also shown that the demise of Lehman was preventable. For instance, the bank's bankruptcy could not have occurred if the US government had not repealed the Glass-Seagal act of 1933. The act would have prevented Lehman from engaging in speculative security trading and investment banking. Also, the act would not have allowed Lehman to grow too big and expose itself to the too big to fail problem. Besides, the analysis showed that a robust corporate governance structure could have prevented bankruptcy. In particular, proper corporate governance would have ensured that Lehman has an adequately constituted bank independent. The board would have provided oversight and closely monitored the bank's operations. A strong governance culture would have also controlled the CEO's power and limited his ability to manipulate the books using Repo 105 procedures. Lastly, Lehman may have avoided bankruptcy if it had received a bailout from the US government. The bank would have used the bailout money to fund operations and stay afloat amidst the crisis.

\subsection{Recommendations}

The downfall of Lehman indicates that regulation and ethical management are critical to the continuity of a business. The analysis shows that the repeal of the GlassSeagal Act 1933 provided an incentive for banks to engage in a high-risk-taking culture which was instrumental in Lehman's collapse (Wilmarth, 2008). The phenomenon calls for an urgent need for the banking and investment industry's tighter supervision to avoid similar scenarios. Therefore, policymakers included the SEC, IFRS, and Basel committee to tighten the banking industry regulation. The good news is that the Basel III accord has introduced stricter regulations and risk management frameworks for banks. For instance, the LCR standard requires banks to maintain an LCR ratio of $100 \%$ (BIS, 2020). Such a requirement will ensure that banks have adequate liquidity and can use the pool of liquid assets during a period of temporary stress (BIS, 2020). Banks must also continually conduct stress tests, identify probable risks, and implement measures to curb the identified risks. The 
Dodd-Frank Act aimed to ensure that banks do not go bankrupt. The act mandates the government to help banks settle their debts and protect their customers (Chadha, 2016). Such measures have strengthened the banking industry and made it more robust than during the 2007/10 financial crisis (Dombret, 2013).

Modification of accounting practices is another measure that can prevent bank failure. In the case of Lehman, the bank effectively used Repo 105 transactions because they were not illegal. However, accounting bodies such as FASB and IAS should develop policies that make it impossible for firms to engage in earnings management. For one, most firms manipulate their accounts by using the loopholes inherent in accounting standards. Therefore, the accounting bodies should create policies that seal the loopholes in the accounting standards. Financial regulatory bodies such as the securities and exchange commission (SEC) and the financial conduct authority should implement stringent measures to bar auditing firms from helping banks deceive investors (Freifeld, 2015). The bodies can, for instance, levy heavy fines and penalties on auditing firms that fail to unearth banks' shortcomings. Such a measure would reduce the likelihood of massive accounting fraud as it would reduce management's capacity and motivation to engage in fraud (Ruankaew, 2016).

The banking industry should also eliminate dubious practices in the banking industry by strictly adhering to ethical practices. In the case of Lehman, the company had developed a code of ethics that applied to all employees. However, the code was not as effective as the top management did not support it. For instance, the CEO disregarded the code by choosing to engage in corrupt accounting practices. He also used the Repo 105 procedure in an unusual and unethical manner to acquire loans by depicting statements to be healthier than they were. Banks should develop a corporate code of ethics to guide employee behavior. Banks should ensure that the ethics code incorporates five principles, including objectivity, confidentiality, integrity, professional competence, and professional behavior. Besides, the code should be supported by the top management and integrated into the banks' corporate strategy. Banks should also implement corporate solid governance frameworks going forward (Kirkpatrick, 2009). Stable corporate governance can prevent the risk factors that led to Lehman bankruptcy. In the case of Lehman, the bank had a weak corporate governance structure that could not safeguard the bank against excessive risktaking (Wiggins et al., 2019). For instance, the bank's board was not independent and professional. Consequently, the bank could not independently verify its operations and ensure that they are carried out ethically. However, a robust corporate governance structure can strengthen the board and ensure that it is independent and adequately constituted (OECD, 2015). The governance structure should also address issues such as conflict of interest, insider dealing, and integrity, critical to sustaining banks as going concerns. Kirkpatrick (2009) adds that a solid corporate governance structure should ensure a qualified board provides oversight and a robust risk management culture. Overall, a robust governance framework can help safeguard banks against excessive risk-taking and the risk of bankruptcy.

Lastly, regulators should invest in and leverage advanced technologies to better understand banks (Chadha, 2016). For instance, big data and analytics investment can 
help regulators detect risky operations within the banking sector and intervene to prevent bankruptcy (Chadha, 2016). Banks should also leverage advanced technology to improve their risk management processes. For instance, big data analytics should help enhance the extrapolative power of their risk models. Banks should also implement machine learning and artificial intelligence to assess risks, improve processes, and prevent fraud and other risks (Donepudi, 2017). The technologies can classify customers based on their repayment habits and credit scores (Donepudi, 2017). Such an application would help banks lend to customers who have good credit scores and avoid default risk.

\section{References}

[1] Azadinamin, A. (2013). The bankruptcy of Lehman brothers: causes of failure recommendations going forward. Social Science Research, 8, 2013.

[2] BIS (2020). Basel III: International framework for liquidity risk measurement, standards, and monitoring. https://www.bis.org/publ/bcbs188.pdf, accessed February 18, 2021

[3] Carney, J. (2010). Report: Lehman Brothers Used "Accounting Gimmick" To Hide the Size of Its Balance Sheet. https://www.businessinsider.com/reportlehman-brothers-used-accounting-gimmick-to-hide-the-size-of-its-balancesheet-2010-3

[4] Chadha, P. (2016). What caused the failure of the Lehman brothers? Could it have been prevented? How. Recommendations for going forward. International Journal of Accounting Research, 1(2), 1-5.

[5] Dombret, A. (2013). Lehman Lessons. The International Economy, 27(4), 34.

[6] Donepudi, P. K. (2017). Machine Learning and Artificial Intelligence in Banking. Engineering International, 5(2), 83-86.

Freifeld, K., 2015. Ernst \& Young settles with N.Y. for $\$ 10$ million over Lehman auditing. https://www.reuters.com/article/us-ernst-lehman-bros idUSKBN0N61SM20150415

[7] Kirkpatrick, G. (2009). The corporate governance lessons from the financial crisis. OECD Journal: Financial market trends, 2009(1), 61-87.

[8] Mawutor, J. K. M. (2014). The failure of Lehman brothers: causes, preventive measures, and recommendations. Research Journal of Finance and Accounting, $5(4)$.

[9] OECD. (2015). G20/OECD Principles of Corporate Governance, OECD Publishing, Paris. http://dx.doi.org/10.1787/9789264236882-en

[10] Presley, T. J., \& Jones, B. (2014). Lehman Brothers: The Case Against SelfRegulation. Journal of Leadership, Accountability \& Ethics, 11(2).

[11] Ruankaew, T. (2016). Beyond the fraud diamond. International Journal of Business Management and Economic Research (IJBMER), 7(1), 474-476.

[12] Trejos, N. (2007). Existing-Home Sales Fall Steeply. https://www.washingtonpost.com/wp-dyn/content/article/2007/04/24/AR2007042400627.html 
[13] Wiggins, R., Piontek, T., \& Metrick, A. (2019). The Lehman Brothers Bankruptcy A: Overview. Journal of Financial Crises: Vol. 1: Iss. 1, 39-62.

[14] Wilmarth, A. E. (2008). Subprime crisis confirms the wisdom of separating banking and commerce. Banking \& Financial Services Policy Report, 27(5), $1-18$. 